\title{
SUBLETHAL EFFECT OF COPPER ON PLASMA CONSTITUENTS OF Cirrhinus mrigala AND Ctenopharyngodon idella
}

\author{
C. Mamatha ${ }^{1 *}$, L. M. Rao ${ }^{2}$, M. S. Chakravarty ${ }^{3}$
}

${ }^{1}$ Mrs. A.V.N. College, Visakhapatnam - 530001,India

${ }^{2}$ Department of Zoology, Andhra University - 530 003, India

${ }^{3}$ Department of Marine Living Resources, Andhra University - 530 003, India

Received - April 25, 2020; Revision - June 1, 2020; Accepted - June 22, 2020

Available Online - June 25, 2020

DOI: http://dx.doi.org/10.18006/2020.8(3).348.354

\section{KEYWORDS \\ Sublethal \\ Copper \\ Plasma \\ C.mrigala \\ C.idella}

Biochemistry

\begin{abstract}
The measurement of serum/plasma parameters is of significance in assessing the nutritive value of cultivable fishes, in the light of drawing waters from contaminated sources and employing biocides containing heavy metals in culture ponds. The main objective of this study was to determine the sublethal effects of copper $(0.16 \mathrm{mg} / \mathrm{l} \mathrm{Cu}$ and $0.53 \mathrm{mg} / \mathrm{l} \mathrm{Cu})$ on plasma glucose, total protein, albumin, globulin, total cholesterol and triglycerides in an endemic carp Cirrhinus mrigala and an exotic carp Ctenopharyngodon idella at weekly intervals, over a period of four weeks. Glucose, albumin, total cholesterol and triglycerides were estimated by enzymatic methods and total protein by non-enzymatic method. Glucose level has elevated on day 14 and then returned to levels comparable to those of control fish. The result of this study revealed that total protein, albumin, cholesterol and triglycerides indicated a positive linear relationship with the duration of exposure. Globulin expressed an intermittent rise and fall till the end of the experiment. All parameters, other than glucose and globulin, showed a gradual decrease with increasing exposure period.
\end{abstract}

* Corresponding author

E-mail: c.mamatha@rediffmail.com (C. Mamatha)

Peer review under responsibility of Journal of Experimental Biology and Agricultural Sciences.

Production and Hosting by Horizon Publisher India [HPI] (http://www.horizonpublisherindia.in/).

All rights reserved.
All the articles published by Journal of Experimental Biology and Agricultural Sciences are licensed under a Creative Commons Attribution-NonCommercial 4.0 International License Based on a work at www.jebas.org.

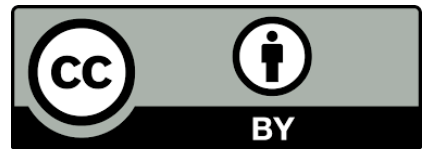




\section{Introduction}

Studies of the chemical composition of fish blood, in general, are fragmentary. Various pollutants bring changes in the blood biochemistry, as a result of metabolic and biochemical processes of an organism. Metabolic changes are indicated by plasma/serum parameters (Luskova et al., 2002). Plasma reflects the pathological and physiological state of the body, and hence measurement of these parameters gives us an understanding of the health status of toxicant stressed fish (Adhikari et al., 2004; Asadi et al., 2006; Bahmani et al., 2010; Kataria et al., 2010; Muñoz et al., 2010). This facilitates an aquaculturist to make sure that the health condition of the animals is unaltered, in order to get a good yield (Farahi et al., 2010; Csep et al., 2010). Various studies revealed that metals can either increase or decrease the blood protein, glucose, cholesterol and serum enzyme activity, depending on the type of the metal, fish species, quality of water and exposure period (Monteiro et al., 2005; Jee et al., 2005).

Glucose is an instant source of energy for the heart and muscles. Unfavourable environmental conditions cause marked elevations in plasma glucose levels. Maintaining normal concentration of glucose is one of the finest homeostatic mechanisms which can be estimated quickly, employing a cost-efficient method (Dobšikova et al., 2009; Nordlie, 2009; Patriche et al., 2010; Shahsavani et al., 2010; Velisek \& Svobodova, 2004). Serum/plasma analysis for total protein, albumin and globulin is significant from a diagnostic point of view, as it not only indicates the general nutritional status of fish, but also a healthy liver and vascular system (Abdel-Tawwab et al., 2008). Total plasma protein content decreases due to impairment of protein synthesis, reduced absorption, or loss of protein (Bernet et al., 2001; Yang \& Chen, 2003). Plasma proteins comprise a mixture of approximately 100 components with different physicochemical properties and functions, some of which are directly involved in fish homeostasis (Petrescu-Mag et al., 2007a; Petrescu-Mag et al., 2007b; Petrescu-Mag et al., 2007c; PetrescuMag \& Petrescu-Mag, 2010). Hence, a measure of plasma proteins is the most important indicator of the nutritional status of fish. Cholesterol, a structural component of cell membranes, forms the outer layer of plasma lipoproteins, and the precursor of all steroid hormones. The negative effect of stress on fish may be observed by a decrease in body lipid content (Svobodova et al., 2006). Reduction in cholesterol and triglyceride content (the most important function of which is to store and provide cellular energy), reflects an increased physiological discomfort or impairment of lipid metabolism (Patriche et al., 2011).

Oner et al. (2008) reported changes in serum parameters of Oreochromis niloticus on exposure to $\mathrm{Ag}, \mathrm{Cd}, \mathrm{Cr}, \mathrm{Cu}$ and $\mathrm{Zn}$ for a prolonged duration. Heydarnejad et al. (2013), investigated the sublethal effects of copper on serum biochemical parameters in rainbow trout. Similarly, Mutlu et al. (2015), worked on alterations in blood chemistry of Nile tilapia, due to affect of long-term exposure to copper sulphate. Various researchers studied the acute effect of copper on blood/plasma biochemical parameters in carps (Khabbazi et al., 2015; Javed et al., 2017; Osman et al., 2019). However, information regarding the chronic effect of copper on blood biochemistry is in paucity. Therefore, present study was carried out to investigate the sublethal effect of copper on the plasma constituents of carps.

\section{Materials and Methods}

Fingerlings, both male and female, of C. mrigala and C. idella, measuring $3 \frac{1}{2} ",-4 "$ and weighing $8 \pm 0.5 \mathrm{~g}$ and $8.5 \pm 1 \mathrm{~g}$ respectively, have been procured from a private fish farmer in Kaikaluru, Andhra Pradesh, India. The fingerlings after prior conditioning, were packed and transported in polythene bags filled with water and oxygen. Immediately after arrival, they were emptied into separate, rectangular fibre glass tubs (200 litres) filled with potable water and pond water in the ratio $1: 1$, with continuous aeration. The fingerlings were allowed to stay overnight. The next day, water in the tanks was exchanged with fresh potable water, and from thereon, every alternate day, tanks were neatly cleaned and water exchange carried for one week. During the week-long acclimation at temperature of $28 \pm 2^{0} \mathrm{C}$, fingerlings were fed with rice bran and oil-cake. They were also observed for parasites, disease and recovery from collection and transport stress. Dead and abnormal individuals were removed periodically. After acclimation, experiments were carried out with both species, by exposing them to sublethal concentrations of copper $(0.16 \mathrm{mg} / \mathrm{l} \mathrm{Cu}$ and $0.53 \mathrm{mg} / \mathrm{l} \mathrm{Cu}$ ), calculated for C. mrigala and C. idella respectively. Aeration was ceased, to avoid alteration in results. Temperature was maintained at $28 \pm 2^{0} \mathrm{C}$. Fish were fed once a week, for the duration of the experiment. Control fish were maintained under similar conditions in water without copper. Groups of 25 fish were exposed to 1/5 of LC50 of copper, in 500 litre fibre-glass tanks, not exceeding $1 \mathrm{~g}$ fish $/ 1$, using static test method.

Every week, control fish and fish from copper concentration were sampled, anaesthetized with $1.5 \mathrm{ppm}$ Quinaldine for 30 minutes, and blood withdrawn from the heart into K3 EDTA vials by piercing $1 \mathrm{ml}$ insulin syringe (disposable). Blood was centrifuged for 15 minutes at $3000 \mathrm{rpm}$, for further analysis. Supernatant plasma was aspirated into $2 \mathrm{ml}$ Eppendorf vials, and stored in a refrigerator at 2-8 ${ }^{0} \mathrm{C}$, and analyzed for total protein, albumin, globulin, glucose, cholesterol and triglycerides, in triplicate. Analysis for glucose was carried out within $24 \mathrm{hrs}$, for cholesterol and triglycerides within $48 \mathrm{hrs}$, and for total protein and albumin within $72 \mathrm{hrs}$ of centrifugation. The intensity of colour for all the parameters has been recorded on GENESYS 10 UV Spectrophotometer. 


\subsection{Glucose}

Plasma glucose was determined by Eco Pak Glucose kit (Accurex Biomedical Pvt. Ltd., India, by enzymatic method (using glucose oxidase and peroxidase) (Young et al.,1976). Glucose oxidase converts glucose to gluconic acid. Hydrogen peroxide formed in the presence of peroxidase, oxidatively couples with 4-aminoantipyrene and phenol to produce red quinoneimine dye. This dye has absorbance maximum of 505 $\mathrm{nm}(500-550 \mathrm{~nm})$. The intensity of the colour complex is directly proportional to the concentration of glucose.

\subsection{Total Plasma Protein}

Total plasma protein was determined by Lowry method (Lowry et al., 1973). The phenolic group of tyrosine and tryptophan residues (aminoacid) in a protein will produce a blue - purple colour complex , which shows maximum absorption of $660 \mathrm{~nm}$ wavelength, with Folin-Ciocalteau reagent and consists of sodium tungstate molybdate and phosphate. The intensity of colour depends on the amount of these aromatic amino acids present, and will thus vary for different proteins.

\subsection{Albumin}

Albumin was determined by Autozyme Albumin kit (Accurex Biomedical Pvt. Ltd., India), based on BCG method (Dumas et al., 1971). Plasma albumin in the presence of Bromocresolgreen, under acidic condition, forms a green coloured complex which has maximum absorption at $600 \mathrm{~nm}(600-650 \mathrm{~nm})$. The absorbance of this complex is proportional to the albumin concentration in plasma.

\subsection{Globulin}

Globulin content was obtained by subtracting plasma albumin in $\mathrm{g}$ / dl from plasma total protein in $\mathrm{g} / \mathrm{dl}$.

\subsection{Total Cholesterol}

Total cholesterol was determined by Infinite Cholesterol kit (Accurex Biomedical Pvt. Ltd., India), based on enzymatic method (Allain et al., 1974). Cholesterol esterase hydrolyses cholesterol esters into free cholesterol and fatty acids. Cholesterol oxidase converts cholesterol to cholest-4-n-3-one and hydrogen peroxide. In the presence of peroxidase, hydrogen peroxide oxidatively couples with 4-aminoantipyrine and phenol to produce red quinoneimine dye which has absorbance maximum at $510 \mathrm{~nm}(500-530)$. The intensity of red colour is proportional to the amount of total cholesterol in the specimen.

\subsection{Triglycerides}

Triglycerides were determined by Infinite Triglycerides kit (Accurex Biomedical Pvt. Ltd., India), based on enzymatic method (Tietz,1994). Glycerol released from hydrolysis of triglycerides by lipoprotein lipase is converted by glycerol kinase into glycerol-3phosphate which is oxidised by glycerol phosphate oxidase to dihydroxy-acetone-phosphate and hydrogen peroxide. In the presence of peroxidase, hydrogen peroxide oxidises phenolic chromogen to a red-coloured compound which has a maximum absorption at $510 \mathrm{~nm}(500-530 \mathrm{~nm})$.

The comparison of the control and treatment groups was statistically analyzed by student's ' $t$ ' test, and the validity of the investigation was expressed as probability ( $p$ ) values. Values of $p$ $<0.05$ were considered significant and $p>0.05$ not significant.

\section{Results and Discussion}

The plasma glucose, total plasma proteins, albumin, globulin, total cholesterol and triglyceride concentrations of the control and treatment groups of C.mrigala and C.idella, are shown in figures $1-6$.

In the present study, it was observed that in copper treatment groups of C.mrigala and C.idella, the selected parameters exhibited a varying trend (compared to those of control), with increase in exposure period. Among the different constituents, a wide range of variation was exhibited by glucose followed by cholesterol and triglycerides, and a narrow range of variation by total plasma proteins (TPP), albumin and globulin. The chronic sublethal copper exposure from $7^{\text {th }}$ to $28^{\text {th }}$ day caused an increase in glucose level, gradual decrease in total protein, albumin, cholesterol and triglycerides, and an intermittent rise and fall in globulin content ( compared to those of control ), in both the species.

The plasma glucose values of the control and treatment groups of C.mrigala and C.idella recorded least values $46.55 \mathrm{mg} / \mathrm{dl}$ and $60.19, \mathrm{mg} / \mathrm{dl}$ and $42.78 \mathrm{mg} / \mathrm{dl}$ and $25.57 \mathrm{mg} / \mathrm{dl}$ on the $28^{\text {th }}$ day respectively. The glucose level of both species has shown a significant increase $(\mathrm{p}<0.05)$ of $249 \%$ and $81 \%$ respectively, on the $14^{\text {th }}$ day (Figure 1 ).

The initial elevation and subsequent reduction of glucose level is in accordance with Heydarnejad et al. (2013), who has reported elevated glucose on exposure to sublethal concentrations of copper in rainbow trout Oncorhynchus mykiss. The higher level of glucose on the 14th day of exposure, may probably be due to glycogenolysis. Glycogenolysis results in high glucose levels under the influence of stress related hormones in organisms 


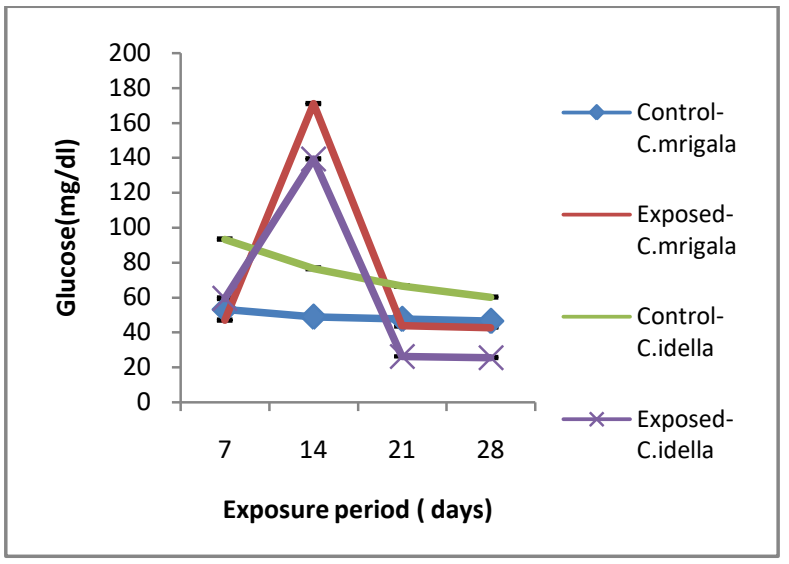

Figure 1 Sublethal effect of copper on plasma glucose levels of $C$. mrigala and C.idella during an exposure period of four weeks

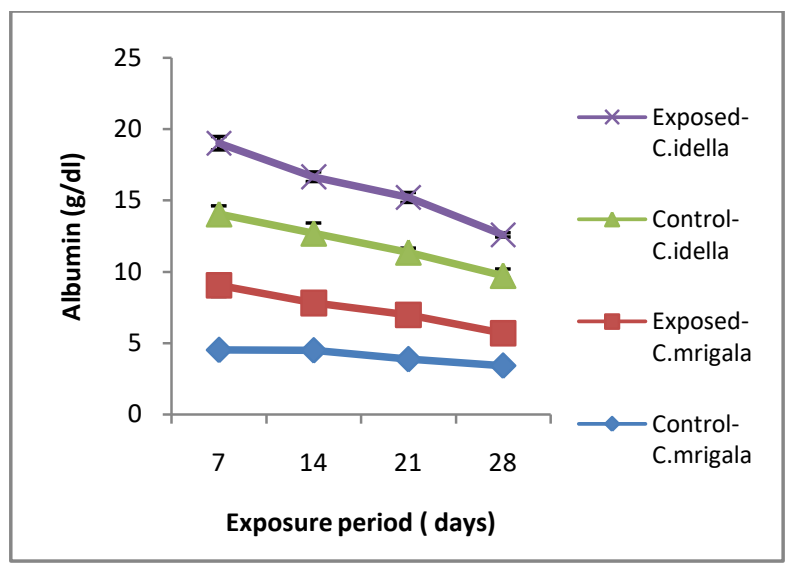

Figure 3 Sublethal effect of copper on plasma albumin content of C.mrigala and C. idella during an exposure period of four weeks

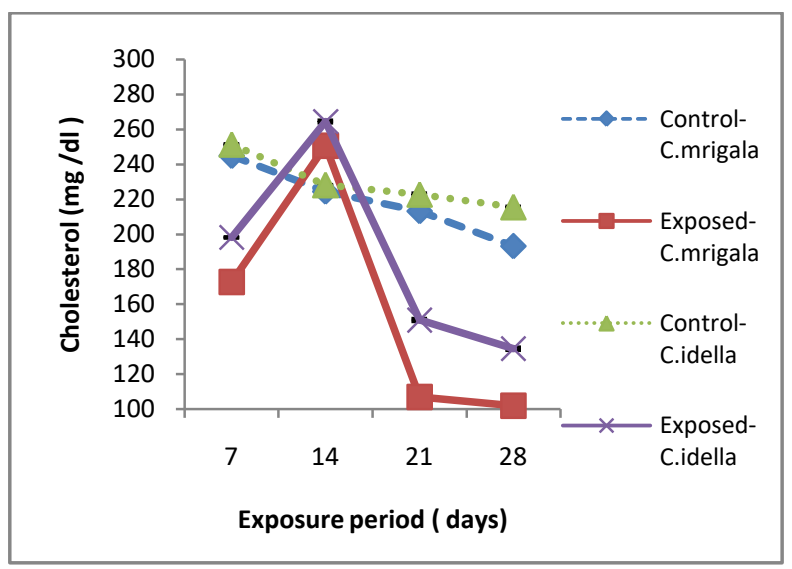

Figure 5 Sublethal effect of copper on plasma cholesterol levels of C.mrigala and C. idella during an exposure period of four weeks.

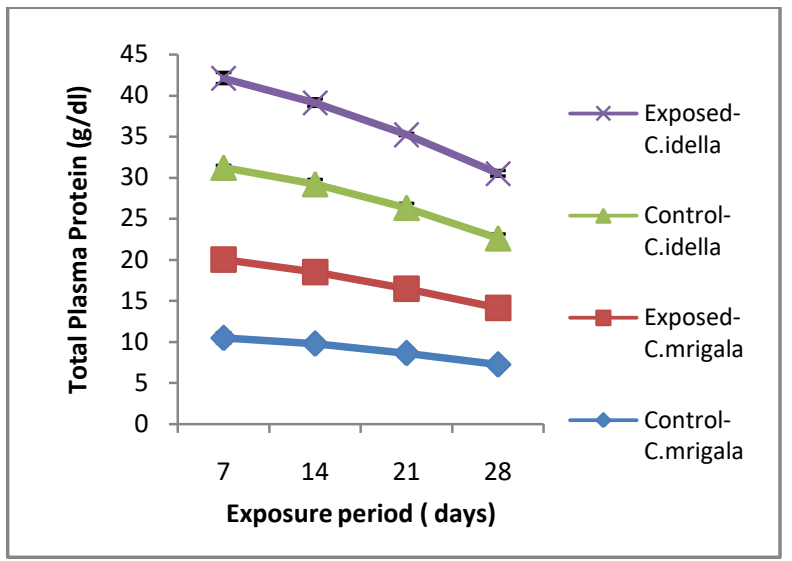

Figure 2 Sublethal effect of copper on total plasma protein of C.mrigala and C. idella during an exposure period of four weeks

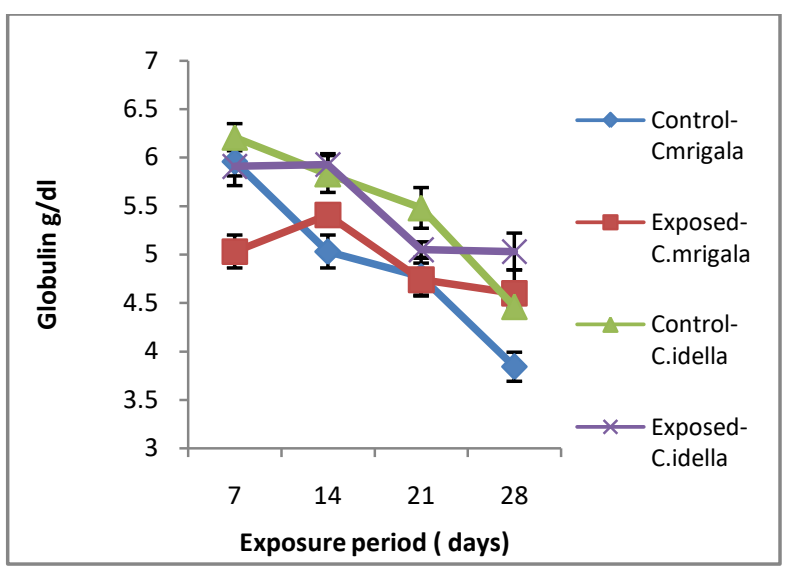

Figure 4 Sublethal effect of copper on plasma globulin content of C.mrigala and C. idella during an exposure period of four weeks

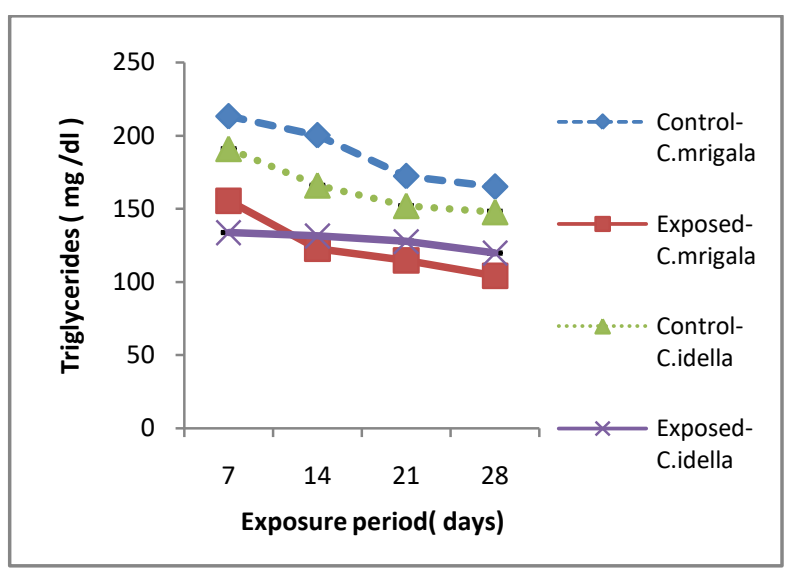

Figure 6 Sublethal effect of copper on plasma triglycerides of C.mrigala and C. idella during an exposure period of four weeks 
(Heydarnejad et al., 2013). Drop in glucose level on the 21 st and 28th days $(\mathrm{p}<0.05$ ) is probably due to depletion of energy reserves. Similar response has been observed by Oner et al. (2008), in copper exposed $O$. niloticus. Alterations in the glucose level might also be related to renal injury, liver damage and lack of nutrition (Oner et al., 2008).

Total plasma proteins, albumin and globulin of the control groups of C.mrigala and C.idella recorded least values of 7.28 and $8.48 \mathrm{~g} / \mathrm{dl}, 3.44$ and $4.02 \mathrm{~g} / \mathrm{dl}$, and 3.84 and $4.46 \mathrm{~g} / \mathrm{dl}$, while those of the treatment groups recorded 6.87 and $7.89 \mathrm{~g} / \mathrm{dl}, 2.27$ and $2.86 \mathrm{~g} / \mathrm{dl}$, and 4.6 and $5.03 \mathrm{~g} / \mathrm{dl}$ respectively, on the 28th day (Figures 2,3,4).

Total protein concentration in the present study decreased significantly in exposed fish, compared to the control value. Oner et al. (2008) reported significant reduction in protein contents of $O$. niloticus, after 30 days of copper exposure and attributed this to differences in exposure concentration and species, or due to changes in the level of serum total protein synthesized mainly in the liver. Stressed condition of fish might probably be the reason for low albumin level in the present study. Similar response has been reported by Mutlu et al. (2015) in O. niloticus and Javed et al. (2017) in Channa punctatus. While hypoalbuminaemia in O. niloticus has been explained to be due to stress situation, that in C. punctatus was said to be due to liver damage (as albumin is produced by liver). Comparable result has also been reported by Eldeen \& Hamid ( 2002). However, stress induced Nile tilapia exposed to individual and combined mixtures of heavy metals, expressed significant increase in total protein and albumin (Firat \& Kargin, 2010). Previous studies revealed that changes in haematological indices of fish caused by heavy metals and their mixtures are different. Globulin level of C.mrigala and C.idella showed intermittent elevation and reduction $(\mathrm{p}=>0.05)$ with increase in exposure period. Similar result has been recorded by Gopal et al. (1997) in C.carpio exposed to sublethal concentration of copper.

Total cholesterol and triglycerides of the control groups of C.mrigala and C.idella recorded least values 193.28 and $215.51 \mathrm{mg} / \mathrm{dl}$, and 165.12 and $147.82 \mathrm{mg} / \mathrm{dl}$ respectively, while those of the treatment groups recorded 101.98 and $134.57 \mathrm{mg} / \mathrm{dl}$, and 104.13 and 119.71 $\mathrm{mg} / \mathrm{dl}$ respectively, on the 28th day (Figures 5,6).

Cholesterol values showed a significant increase $(\mathrm{p}=<0.05)$ on the $14^{\text {th }}$ day, and then decreased towards the end of the exposure period. It has been revealed by earlier studies that cholesterol concentrations in serum of copper exposed fish generally increase. Similar trend in cholesterol values of copper stressed fish, was described by Oner et al. (2008) in O. niloticus, Heydarnejad et al. (2013) in O. mykiss and Yang \& Chen ( 2003) in gallium stressed Cyprinus carpio. The probable reason for high cholesterol levels may be liver and kidney failure causing the release of cholesterol into the bloodstream (Oner et al., 2008). The increase in cholesterol concentrations is due to hazardous effects of copper, particularly on cell membrane (Heydarnejad et al., 2013).

Triglyceride concentration in plasma of copper-exposed fishes showed significant decrease. Oner et al. (2008) reported a similar effect in $O$. niloticus exposed to copper, and a severe reduction in triglyceride levels after 20 days of exposure. Similarly, reduction in serum triglyceride concentrations of $O$. mykiss, was observed by Heydarnejad et al. (2013) after 15 days of exposure. Fishes exposed to copper show inconsistent triglyceride concentrations, because lipid metabolism and glycogen storage are different for different fish species, in addition to variation in exposure period (Heydarnejad et al., 2013). It can be concluded that the studied blood parameters can not only be employed as ideal biomarkers to monitor the well being of the farmed fishes, but the responses of these biomarkers can also be related to population parameters, enabling comparison of predictions from computer-based models in risk assessment of aquatic environments.

\section{Conflict of Interest}

Authors would hereby like to declare that there is no conflict of interests that could possibly arise.

\section{Acknowledgements}

I am thankful to the University Grants Commission for selecting me under the Faculty Development Programme (FDP) during the $\mathrm{XI}$ plan, and extending financial support to pursue my Ph.D.

\section{References}

Abdel-Tawwab M, Abdel-Rahman AM, Ismael NEM (2008) Evaluation of commercial live baker's yeast, Saccharomyces cerevisiae as a growth and immunity promoter for fry Nile tilapia, Oreochromis niloticus (L.) challenged in situ with Aeromonas hydrophila. Aquaculture 280: 185-189

Adhikari S, Sarkar B,Chatterjee A, Mahapatra CT, Ayyappan S (2004) Effects of cypermethrin and carbofuran on certain hematological parameters and prediction of their recovery in a freshwater teleost, Labeo rohita (Hamilton). Ecotoxicology and Environmental Safety 58: 220-226

Allain CC, Poon LS, Chan CSG, Richmond W, Fu PC (1974) Enzymatic determination of total serum cholesterol. Clinical Chemistry 20 (4) :470- 475

Asadi F, Masoudifar M, Vajhi A (2006) Serum biochemical parameters of Acipenser persicus. Fish Physiology and Biochemistry 32:43-47 
Bahmani M, Kazemi R, Donskaya PA (2010) Comparative study of some hematological features in young reared sturgeons (Acipenser persicus and Huso huso). Fish Physiology and Biochemistry 24:135-140

Bernet D, Schmidt H, Wahli T, Burkhardt-Holm P (2001) Effluent from a sewage treatment works causes changes in serum chemistry of brown trout (Salmo trutta L.) Ecotoxicology and Environmental Safety 48:140-147

Csép L, Bud I, Chirila F (2010) Disease resistance effect of seabuckthorn (Hippophaerhamnoides L.) added in the fish diet. Aquaculture, Aquarium, Conservation \& Legislation International Journal of the Bioflux Society 3(5):339-34

Dobšikova R, Svobodova Z, Blahova J (2009) The effect of transport on biochemical and haematological indices of common carp (Cyprinus carpio L.). Czech Journal of Animal Science 54(11): 510-518

Dumas BT, Watson WA, Biggs HG (1971) Albumin standards and the measurement of serum albumin with bromocresol green. Clinica Chimica Acta 31: 87-96

Eldeen KS, Hamid NAA (2002) Sublethal effects of copper sulfate, malathion and paraquat on protein pattern of Oreochromis niloticus. Egyptian Journal of Aquatic Biology and Fisheries 6(2):167-182

Farahi A, Kasiri M, Sudagar M (2010) Effect of garlic (Allium sativum) on growth factors,some hematological parameters and body compositions in rainbow trout (Oncorhynchus mykiss). Aquaculture, Aquarium, Conservation \& Legislation 3(4):317-323

Firat O, Kargin F (2010) Individual and combined effects of heavy metals on serum biochemistry of Nile tilapia Oreochromis niloticus. Archives of Environmental Contamination and Toxicology 58: 151-157

Gopal V, Parvathy S, Balasubramanian PR (1997) Effect of heavy metals on the blood protein biochemistry of the fish Cyprinus carpio and its use as a bioindicator of pollution stress. Environmental Monitoring and Assessment48:117-124, 1997.

Heydamejad MS, Mojdeh Khosravian-hemami K, Amin Nematollahi A, Rahnama S (2013) Effects of copper at sublethal concentrations on growth and biochemical parameters in rainbow trout (Oncorhynchus mykiss). International Review of Hydrobiology 98 (2): $71-79$.

Javed M, Ahmed MI, Usmani N, Ahmad M (2017) Multiple biomarker responses (serum biochemistry, oxidative stress, genotoxicity and histopathology) in Channa punctatus exposed to heavy metal loaded waste water. Scientific Reports 7(1):1675. doi: 10.1038/s41598-017-01749-6.

Jee JH, Masroor F, Kang J C (2005) Responses of cypermethrininduced stress in haematological parameters of Korean rockfish, Sebastes schlegeli (Hilgendorf). Aquaculture Research 36 (9): 898-905

Kataria N, Kataria AK, Pandey N, Gupta P (2010) Serum biomarkers of physiological defense against reactive oxygen species during environmental stress in Indian dromedaries. Human and Veterinary Medicine Bioflux 2(2):55-60

Khabbazi M, Harsij M, Hedayati SAA, Gholipoor H, Gerami MH, Farsani HG ( 2015) Effect of $\mathrm{CuO}$ nanoparticles on some hematological indices of rainbow trout Oncorhynchus mykiss and their potential toxicity. Nanomedicine Journal 2(1): 67-73

Lowry OH, Rosenberg NJ, Para A, Randall RJ (1973) Protein measurement with Folin phenol reagent. Journal of Biological Chemistry 193: 267-275

Luskova V, Svoboda M, Kolarova J (2002) The effect of Diazinon on blood plasma biochemistry in carp (Cyprinus carpio L.). Acta Veterinaria Brno 71: 117-123

Monteiro SM, Mancera JM, Fontainhas Fernandes A, Sousa M (2005) Copper induced alterations of biochemical parameters in the gill and plasma of Oreochromis niloticus. Comparative Biochemistry and Physiology C. 141: 375-383

Muñoz A, Riber C, Trigo P, Castejón F (2010) Pathological changes and clinical use of the measurement of serum/plasma concentrations of insulin-like growth factor type1(IGF-1) in horses, dogs and cats. Human and Veterinary Medicine Bioflux $2(2): 39-54$

Mutlu E, Aydn S, Kutlu B (2015) Alterations of Growth Performance and Blood Chemistry in Nile Tilapia (Oreochromis niloticus) Affected by Copper Sulfate in Long-Term Exposure. Turkish Journal of Fisheries and Aquatic Sciences, 15: 487- 493

Nordlie FG (2009) Environmental influences on regulation of blood plasma/serum components in teleost fishes. Reviews in Fish Biology and Fisheries 19:481-564

Oner M, Atli G, Canli M (2008) Changes in serum parameters of freshwater fish Oreochromis niloticus following prolonged metal $(\mathrm{Ag}, \mathrm{Cd}, \mathrm{Cr}, \mathrm{Cu}, \mathrm{Zn})$ exposures. Environmental Toxicology and Chemistry 2: 360-366.

Osman AGM, Said REM, Hasieb HE, Moustafa MA, Soliman SME, Kloas W (2019) "Haematological, serological and genotoxic findings in the African catfish Clarias gariepinus after the 
administration of copper nanoparticles and Penconazole". E Cronicon Veterinary Science 4 (10) : 01-14

Patriche T, Patriche N, Bocioc E, Coada MT (2011) Serum biochemical parameters of farmed carp (Cyprinus carpio). Aquaculture, Aquarium, Conservation \& Legislation 4(2): $137-$ 140

Patriche T, Patriche N, Bocioc E (2010) Serum biochemical parameters of juvenile stages of the Ossetra sturgeon Acipenser güldenstaedti (Brandt, 1833). Bulletin of the University of Agricultural Sciences and Veterinary Medicine Cluj-Napoca, 67:300-303

Petrescu-Mag IV, Botha M, Oroian I, Odagiu A, Petrescu-Mag RM (2007c) Latimeria review: intronless HSP70 gene in the extant coelacanth species L. chalumnae and L. menadoensis (Sarcopterygii, Latimeriidae). Extreme Life, Biospeology and Astrobiology Bioflux Pilot :15-22.

Petrescu-Mag IV, Botha M, Petrescu-Mag RM (2007a) Heat shock proteins in fish - a review. Extreme Life, Biospeology and Astrobiology Bioflux Pilot:1-10

Petrescu-Mag IV, Oroian I, Petrescu-Mag RM (2007b) The coldwater tolerance in Trematomus bernacchii, Boulenger 1902, and the heat shock proteins implications. Extreme Life, Biospeology and Astrobiology Bioflux Pilot:11-14
Petrescu-Mag IV, Petrescu-Mag RM (2010) Heavy metal and thermal stress in fishes:The implications of HSP in adapting and acclimation to different environments. Metalurgia International 15(10):107-117

Shahsavani D, Kazerani HR, Kaveh S, Gholipour-Kanani H (2010) Determination of some normal serum parameters in starry sturgeon (Acipenser stellatus Pallas, 1771) during spring season. Comparative Clinical Pathology 19:57-61

Svobodova Z, Vykusova B, Modra H, Jarkovsky J, Smutna M (2006) Haematological and biochemical profile of harvest-size carp during harvest and post-harvest storage. Aquaculture Research 37: 959-965

Tietz NW (1994) Clinical Guide to Laboratory Tests, $2^{\text {nd }}$ ed.,W.B.Saunders, Philadelphia, pp. 1073-1091

Velisek J, Svobodova Z (2004) Anaesthesia of common carp (Cyprinus carpio L.) with 2-phenoxyethanol: Acute toxicity and effects on biochemical blood profile. Acta Veterinaria Brno 73:247-252

Yang J, Chen HC ( 2003 ) Effects of gallium on common carp (Cyprinus carpio): Acute test, serum biochemistry and erythrocyte morphology. Chemosphere $53: 877-882$

Young DS, Pestaner LC, Gibberman V (1976) Effects of drugs on clinical laboratory tests. Clinical Chemistry 21(5): 1 D - 432D 